\title{
Endoscopic Management of Post-Polypectomy Bleeding
}

\author{
Aditya Gutta and Mark A. Gromski \\ Division of Gastroenterology and Hepatology, Department of Medicine, Indiana University School of Medicine, Indianapolis, IN, USA
}

Post-polypectomy bleeding (PPB) is one of the most common complications of endoscopic polypectomy. There are multiple risk factors related to patient and polyp characteristics that should be considered. In most cases, immediate PPB can be effectively managed endoscopically when recognized and managed promptly. Delayed PPB can manifest in a myriad of ways. In severe delayed PPB, resuscitation for hemodynamic stabilization should be prioritized, followed by endoscopic evaluation and therapy once the patient is stabilized. Future areas of research in PPB include the risks of direct oral anticoagulants and of specific electrosurgical settings for hot-snare polypectomy vs. cold-snare polypectomy, benefits of closure of post-polypectomy mucosal defects using through-the-scope clips, and prospective comparative evaluation of newer hemostasis agents such as hemostatic spray powder and over-the-scope clips. Clin Endosc 2020;53:302-310

Key Words: Colonoscopy; Complication; Hematochezia; Polypectomy; Post-polypectomy bleeding

\section{INTRODUCTION}

Colonoscopy with polypectomy is the gold standard for removing precancerous polyps of the colon. The process of identification and removal of polyps during colonoscopy has been demonstrated to decrease the risk of colon cancer development in individuals. ${ }^{1}$ However, polypectomy during colonoscopy carries risks, including post-polypectomy bleeding (PPB), post-polypectomy syndrome, and perforation. PPB can be categorized into two groups: immediate PPB and delayed PPB. In immediate PPB, the endoscopist can almost always identify a bleeding complication at the time of polypectomy and perform endoscopic therapy at that time. Delayed PPB usually manifests hours to days after colonoscopy, with the patient presenting with signs or symptoms of hematochezia,

\section{Received: March 3, 2019 Revised: July 18, 2019}

Accepted: July 18, 2019

Correspondence: Mark A. Gromski

Division of Gastroenterology and Hepatology, Department of Medicine, Indiana University School of Medicine, 550 N. University Blvd., Suite 1634, Indianapolis, IN 46202, USA

Tel: +1-317-944-0980, Fax: +1-317-968-1265, E-mail: mgromski@iu.edu ORCID: https://orcid.org/0000-0002-9035-2434

(c) This is an Open Access article distributed under the terms of the Creative Commons Attribution Non-Commercial License (http://creativecommons.org/ licenses/by-nc/3.0) which permits unrestricted non-commercial use, distribution, and reproduction in any medium, provided the original work is properly cited. acute blood loss anemia with possible hemodynamic instability, and end-organ damage (acute kidney injury, syncope, chest pain, dyspnea, etc.). A patient with significant hematochezia hours to days after colonoscopy should always raise a suspicion for delayed PPB. Although similar bleeding complications can occur after resection of polyps in the foregut, this review will focus on the current approaches in the management of PPB resulting from polypectomy in the colon.

\section{RISK FACTORS}

A number of patient-specific and polyp-specific risk factors have been identified in association with polypectomy (Table 1). A large study (including 15,285 colonoscopies) on PPB resulting from colonoscopies, performed as part of the English National Health Service Bowel Cancer Screening Programme, demonstrated the rate of PPB to be $0.4 \%$ per colonoscopy performed in patients at a high risk of colon polyps (positive fecal occult blood stool test). ${ }^{2}$ A systematic review and meta-analysis of studies on colorectal neoplastic lesions $\geq 20 \mathrm{~mm}$ that were managed with endoscopic polypectomy demonstrated that in 6,474 colonoscopies with large-polyp polypectomy, the rate of bleeding was $6.5 \%$, which was significantly higher than that for small-polyp polypectomy. ${ }^{3}$ 
A study by Kim et al. that included 5,152 patients undergoing colonoscopy (in which $>9,000$ polyps were removed) showed multiple risk factors for immediate PPB. ${ }^{4}$ Polyp-based multivariate analysis showed that age $\geq 65$ years, comorbid cardiovascular or chronic renal disease, anticoagulant use, polyp size $>1 \mathrm{~cm}$, laterally spreading polyp, thick polyp stalk, poor bowel preparation, and inadvertent cutting of a polyp before the intended application of current were all significant risk factors of PPB. ${ }^{4}$

A large study by Zhang et al. that included 15,553 polypectomies showed multiple risk factors for delayed PPB. ${ }^{5}$ Polyp size $>10 \mathrm{~mm}$ (odds ratio [OR], 4.6; 95\% confidence interval [CI], 2.9-7.2), immediate PPB (OR, 2.9; 95\% CI, 1.4-5.9), and colon polyp pathology (juvenile polyp: OR, 4.3; 95\% CI, 1.8-11, Peutz-Jegher polyp: OR, 3.3; 95\% CI, 1.0-10.7) were all associated with increased rates of PPB. ${ }^{5}$ Another recent casecontrol study demonstrated that polyp size and location in the colon were independent risk factors for delayed PPB. ${ }^{6}$ The risk of bleeding increased by $13 \%$ for every $1 \mathrm{~mm}$ increase in polyp diameter. Polyps located in the right colon were more likely to bleed than those in the left colon or rectum (OR, 4.7; 95\% CI, 1.9-11.6). ${ }^{6}$ A study of the English National Health Service Bowel Cancer Screening Programme supported these findings. ${ }^{7}$ Of 130,831 colonoscopies with 167,208 polypectomies, the major risk factors for PPB were cecal location and increasing polyp size. ${ }^{7}$ After adjustment for polyp size, the OR of PPB for a cecal polypectomy was found to be 13.5 (95\% CI, 3.9-46.4).

Uninterrupted antiplatelet agents (APAs) and anticoagulant medications have also been associated with higher rates of PPB. A recent systematic review and meta-analysis of 11

Table 1. Risk Factors Associated with Polypectomy

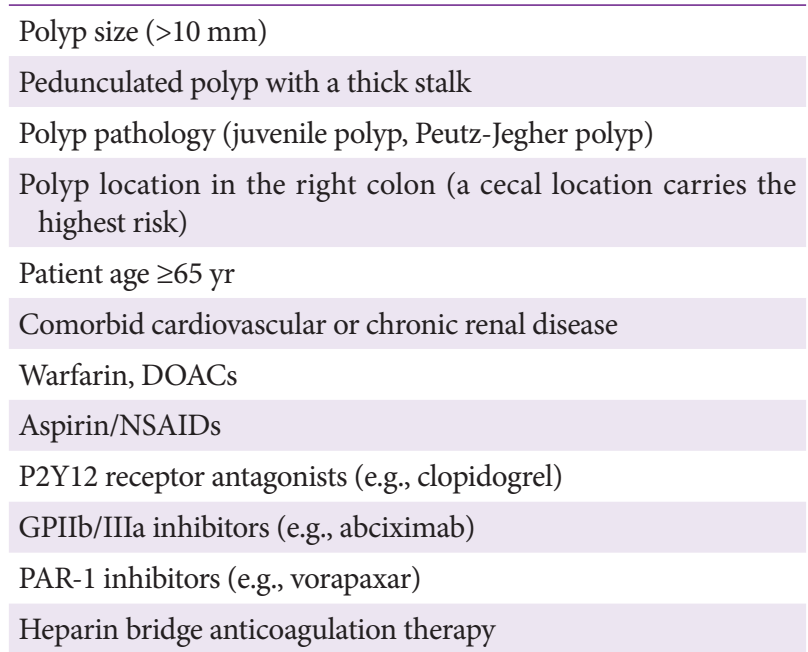

DOACs, direct oral anticoagulants; NSAID, nonsteroidal anti-inflammatory drug; PAR-1, protease-activated receptor-1. studies (with 9,307 patients) showed that use of aspirin and/ or nonsteroidal anti-inflammatory drugs (NSAIDs) was not a risk factor for immediate PPB (OR, 1.1; 95\% CI, 0.6-2.1), but increased the risk of delayed PPB (OR, 1.7; 95\% CI, 1.2-2.2). ${ }^{8}$ Furthermore, there is evidence of an increased risk of $\mathrm{PPB}$ while on clopidogrel treatment (OR, 9.7; 95\% CI, 3.1-30.8) and with the combination of clopidogrel + aspirin (dual antiplatelet therapy) and/or NSAIDs (OR, 3.4; 95\% CI, 1.3-8.8). ${ }^{9}$ Studies have demonstrated increased rates of PPB in both the immediate and delayed settings. ${ }^{10}$ There have been reports of PPB rates as high as $22 \%$ in cases of colonoscopy with polypectomy performed with prophylactic clip closure in patients who are on heparin bridge anticoagulant therapy (compared with the rate of $1.9 \%$ in patients not on heparin bridge therapy in this study). ${ }^{11}$ Similar risks of delayed PPB with heparin bridge therapy have also been noted in other studies. ${ }^{12,13} \mathrm{~A}$ higher risk of PPB (51.7\%) was noted in patients undergoing endoscopic mucosal resection (EMR) while on heparin bridge therapy. ${ }^{14}$ Continued warfarin use has also previously been found to have an increased risk of PPB (OR, 13.4; 95\% CI, 4.1-43.7). ${ }^{15}$ Increased costs of hospitalization have also been reported in association with heparin bridge therapy. A recent study ${ }^{16}$ showed a 10-fold higher risk of PPB in patients on heparin bridge anticoagulation therapy than in those on interrupted warfarin therapy. Other risk factors for PPB were also identified and found to be similar to those reported in other studies (Table 1$)^{17}$

With the advent of newer APAs and direct oral anticoagulants (DOACs) over the past few years, there has been an increasing need to study the effects of these agents on PPB and to identify risk factors that predispose patients to PPB. A study by Beppu et al. has shown that edoxaban (a direct factor Xa inhibitor) had the lowest PPB rate among the four current DOACs on the market and the use of DOACs (interrupted 1 day before the treatment procedure and restarted within $24 \mathrm{~h}$ after the procedure in this study) carried a similar safety profile, decreased the rate of delayed PPB, and reduced the length of hospital stay, compared with heparin bridge therapy. ${ }^{18} \mathrm{~A}$ similar study by Yanagisawa et al. ${ }^{19}$ showed comparable rates of delayed PPB between warfarin and all DOACs (no patients on edoxaban). Predictive models for PPB in patients receiving warfarin and DOACs, such as the Outcomes Registry for Better Informed Treatment score ${ }^{20}$ and a risk-scoring model from China, ${ }^{21}$ have been proposed but are yet to be validated for widespread use. There are also studies reporting the risk of PPB with hot-snare (thermal) polypectomy (HSP) and coldsnare (nonthermal) polypectomy (CSP) in the background of APAs, warfarin, and DOACs, which are detailed in the next section. Overall, comprehensive prospective studies assessing the risk of PPB associated with newer APAs and DOACs are 
lacking and need to be addressed in the immediate future.

\section{PREVENTION OF POST-POLYPECTOMY BLEEDING}

In patients taking APAs and anticoagulant medications, withholding these medications in the peri-colonoscopic period can pose significant risks of thrombo-embolic and cardiac events. Thus, the risk of withholding these medications must be carefully weighed against that of PPB. A review by Baron et $\mathrm{al}^{22}$ on the management of antithrombotic therapy in patients undergoing invasive procedures in all specialties was published in 2013, which classified nonthermal polypectomy (CSP) of small colonic polyps $(<10 \mathrm{~mm})$ as a low-risk procedure and thermal polypectomy (HSP) of large polyps $(\geq 10 \mathrm{~mm}$ ) as well as EMR as high-risk procedures. The review made appropriate recommendations about the discontinuation and resumption of APAs and anticoagulants based on the bleeding risk of the procedure and risk of thrombo-embolic events on discontinuation of antithrombotic therapy. Thereafter, specific guidelines have been issued by the American Society for Gastrointestinal Endoscopy (ASGE) ${ }^{23}$ and the British Society of Gastroenterology/European Society of Gastrointestinal Endoscopy (ESGE) ${ }^{24}$ both in 2016, regarding the peri-procedural management of antithrombotic medications specifically for gastroenterological procedures. Both sets of guidelines have classified polypectomy (thermal and nonthermal) and EMR as high-risk procedures and have risk-stratified the indications for antithrombotic medications. Based on the risk assessment of indications for antithrombotic therapy, the risk of thrombo-embolic events on discontinuation, characteristics (pharmacokinetics and pharmacodynamics) of individual agents, and comorbidities of individual patients, recommendations have been provided for currently approved APAs and anticoagulants with respect to the timing of discontinuation before the procedure, need for heparin bridging, and timing of resumption after procedure completion. The guidelines also advise caution in high-risk indications for antithrombotic therapy and recommend liaising with the prescribing specialist (cardiologist, neurologist, etc.) regarding the timing of discontinuation. The two sets of guidelines are similar with respect to polypectomy, with the ASGE providing expanded recommendations on individual DOACs based on the patient's creatinine clearance. Experts recommend using these guidelines to create individual plans for patients based on their individual characteristics and comorbidities. The guidelines published by the Japan Gastroenterological Endoscopy Society in 2013, ${ }^{25}$ with an update in 2017 specifically addressing DOACs, ${ }^{26}$ and those published by the Asian Pacific Association of Gastro-
enterology/Asian Pacific Society for Digestive Endoscopy ${ }^{27}$ in 2018 have also provided similar recommendations.

There has been significant interest in the past few years in the individual bleeding risk associated with polypectomy of small $(<10 \mathrm{~mm})$, large $(10-19 \mathrm{~mm})$, and very large $(\geq 20 \mathrm{~mm})$ polyps; in the individual bleeding risk associated with thermal polypectomy (HSP) and nonthermal polypectomy (CSP); and in modalities that can be deployed at the time of polypectomy to prevent immediate and/or delayed PPB.

There is evidence of a lower rate of delayed PPB with CSP than that with HSP. Individual studies ${ }^{28,29}$ and systematic reviews and meta-analyses ${ }^{30}$ have shown that although HSP minimizes immediate PPB through thermal therapy, it carries a risk of damage to the deeper tissues and blood vessels, leading to delayed PPB. CSP, on the other hand, is associated with immediate PPB that can be treated at the time of polypectomy and with much lower delayed PPB rates. Meanwhile, the two techniques have comparable resection rates. A recent study ${ }^{31}$ showed that the depth and size of the mucosal defect on the day after polypectomy was greater with HSP than with CSP, and this finding may also partially account for the higher rates of delayed PPB with HSP. The decision to use HSP is primarily determined by the polyp size and morphology (pedunculated vs. nonpedunculated). Most polyps encountered during colonoscopy are either diminutive $(<5 \mathrm{~mm})$ or small $(6-9 \mathrm{~mm})$ nonpedunculated polyps. The current ESGE guidelines ${ }^{32}$ recommend CSP as the preferred technique for the removal of subcentimeter $(<10 \mathrm{~mm})$ polyps, with a recent meta-anal$\mathrm{ysis}^{33}$ supporting this recommendation. A recent multicenter randomized controlled trial ${ }^{34}$ showed that CSP is not inferior (comparable resection rate) to HSP for small nonpedunculated polyps with a superior safety profile (lower delayed PPB rate). These findings were also supported by a recent meta-analysis ${ }^{35}$ that did not include the randomized controlled trial $^{34}$ There has been a concerted effort to expand the use of CSP to large nonpedunculated polyps ( $\geq 10 \mathrm{~mm}$ ). Recent systematic reviews and pooled-analyses ${ }^{36,37}$ showed excellent rates of resection comparable to those of HSP, with lower rates of delayed PPB than those of HSP. There were higher rates of immediate PPB with polyps $\geq 20 \mathrm{~mm}$, which were effectively managed during the procedure.

Expanding the application of CSP to small pedunculated polyps $(\leq 10 \mathrm{~mm})$ has also been considered, with a recent study ${ }^{38}$ showing low rates of immediate PPB in procedures involving endoscopic clipping and showing no delayed $\mathrm{PPB}$. Further studies are required to assess the safety of CSP for pedunculated polyps. The general practice remains HSP for pedunculated polyps, given that penetrating blood vessels within the stalk is not uncommon.

As previously mentioned, the presence of antithrombotic 
medications (APAs, warfarin, DOACs) further adds complexity to determining the safety of CSP and HSP and the rates of associated immediate and delayed PPB. Several studies ${ }^{39-41}$ and a prospective, multicenter, randomized controlled trial ${ }^{42}$ have shown the safety of CSP for subcentimeter nonpedunculated polyps $(<10 \mathrm{~mm})$ in the presence of continued use of APAs, warfarin, and DOACs with no increased risk of delayed $\mathrm{PPB}$ compared with $\mathrm{HSP}^{43}$ even when multiple antithrombotic agents ${ }^{44}$ were continued.

There is controversy about whether clipping mucosal defects (Fig. 1) after polypectomy (HSP and CSP) may reduce the risk of subsequent delayed PPB. In a study of 524 large polyps $(\geq 2 \mathrm{~cm})$ in which $47.1 \%$ were not clipped and the others were clipped, there was a significantly decreased risk of delayed PPB in the group with prophylactic clipping of resection sites (1.8\% clipped vs. $9.7 \%$ not clipped). ${ }^{45}$ Multivariate analysis showed that the absence of clipping (OR, 6.0; 95\% CI, 2.0-18.5), a location proximal to the splenic flexure (OR, 2.9; $95 \%$ CI, 1.1-8.1), and polyp size were all associated with delayed PPB. ${ }^{45} \mathrm{~A}$ subsequent multicenter randomized controlled study of prophylactic clipping vs. nonclipping polypectomy sites in polyps $<2 \mathrm{~cm}$ showed no significant difference between the two groups, suggesting a lack of benefit with clipping mucosal defects for polyps $<2 \mathrm{~cm}^{46}$ More recent studies have also reported similar findings, showing that prophylactic clipping of mucosal defects following polypectomy of nonpedunculated polyps $<20 \mathrm{~mm}$ and irrespective of location has not been effective in reducing the risk of delayed PPB, and is associated with higher costs with no definite benefits. ${ }^{47,48}$ In a recent multicenter, randomized trial of 1,900 patients undergoing polypectomy of large nonpedunculated colon polyps ( $\geq 20 \mathrm{~mm}$ ), endoscopic clip closure of the mucosal defect was found to reduce the risk of PPB (3.3\% vs. 9.6\%) and the risk reduction appeared to be largely limited to polypectomies performed in the proximal colon. ${ }^{49}$ In contrast, in a separate randomized trial in 1,098 patients undergoing polypectomy of nonpedunculated polyps $\geq 10 \mathrm{~mm}$, there was no benefit with closure of mucosal defects using prophylactic endoscopic clipping in reducing the rate of delayed PPB, and this finding was consistent with that obtained for large polyps $(\geq 20 \mathrm{~mm}){ }^{50}$ Several systematic reviews and meta-analyses ${ }^{51-56}$ have consistently shown a similar lack of benefit of prophylactic endoscopic clipping of mucosal defects of nonpedunculated polyps up to $19 \mathrm{~mm}$, with inconclusive benefits for nonpedunculated polyps $\geq 20 \mathrm{~mm}$. This heterogeneity in polyps $\geq 20 \mathrm{~mm}$ could be due to variations in the polyp location that have not been accounted for in most studies, as was reported in the previously mentioned randomized trial ${ }^{49}$ in which a benefit was noted only in the proximal colon. A recent study ${ }^{57}$ proposed the use of a Doppler endoscopic probe to detect superficial $(<4 \mathrm{~mm})$ arterial blood flow in the post-polypectomy mucosal defect to identify lesions that would benefit from prophylactic endotherapy (clipping, thermal therapy) and showed that mucosal defects $\geq 15 \mathrm{~mm}$ more likely contain arterial blood flow. Defects with arterial flow have a much higher risk of delayed PPB and may benefit from prophylactic endotherapy. This technology appears to be promising in detecting highrisk lesions and would need further prospective study before widespread implementation can be recommended. Another study proposed thermal therapy of visible vessels seen after EMR, with the results showing no benefit in the reduction of delayed PPB, supporting our previously mentioned hypothesis that delayed PPB primarily results from damage to vessels in deeper tissues during HSP. To avoid injury to deeper tissues in

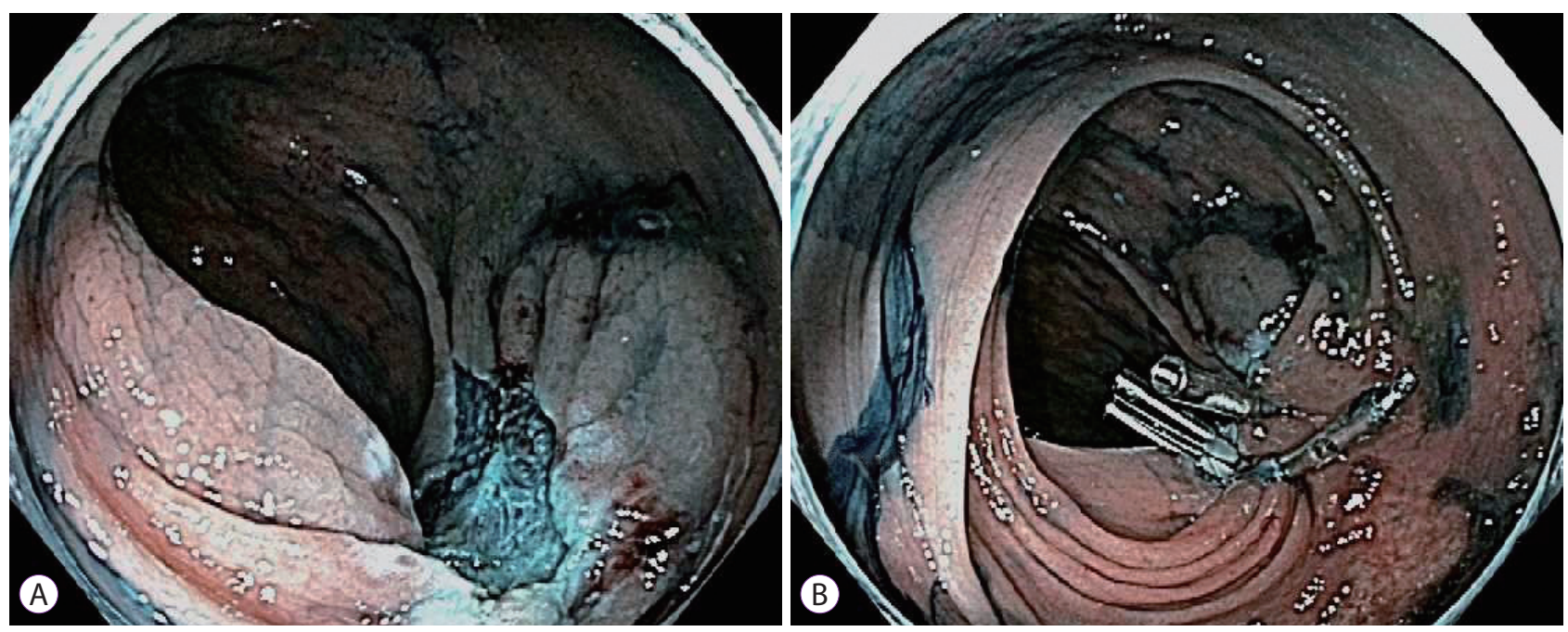

Fig. 1. (A) Colonic mucosal defect status after endoscopic mucosal resection (EMR). (B) Multiple endoscopic through-the-scope clips is deployed to close the EMR mucosal defect. 
HSP, a recent study ${ }^{58}$ compared the two most commonly used electrocautery settings and found no difference in the rates of resection or rates of delayed PPB.

Previous studies have suggested a potential benefit of performing prophylactic submucosal injection of an epinephrine solution before polypectomy. ${ }^{59,60}$ These studies, however, have been limited by their small size. A more definitive prospective, randomized multicenter trial of prophylactic injection of epinephrine solution before the resection of large colon polyps $(>10 \mathrm{~mm})$ showed no significant difference in the immediate or delayed PPB rates in patients who received submucosal injection of epinephrine solution. ${ }^{61}$

Given the increased risk of immediate PPB associated with large pedunculated polyps with thick stalks, some endoscopists routinely place a detachable snare (endoloop) around the stalk of a large pedunculated polyp before polypectomy. In a prospective, randomized study on the placement of a detachable snare on the stalk of a pedunculated polyp combined with injection of epinephrine solution compared with sole injection of epinephrine solution, there was a significantly decreased risk of immediate PPB in the combination group treated with detachable snare compared to the group given epinephrine injection alone. ${ }^{62} \mathrm{~A}$ systematic review and meta-analysis recently demonstrated that both prophylactic mechanical therapy and injection therapy reduced immediate PPB, but had no effect on delayed PPB. The combination of both therapies, however, was not significantly better than either therapy alone. ${ }^{63}$

\section{MANAGEMENT OF POST-POLYPECTOMY BLEEDING}

The management of immediate PPB is relatively straightforward, if detected and addressed at the time of polypectomy. Every polypectomy resection site should be routinely examined after resection to check for the presence of muscle tissue (deep) injury, perforation, residual polyp, or bleeding. In the case of minimal oozing of blood from a polypectomy site (Fig. 2), a small period of observation with water lavage often results in self-limited cessation of oozing. Further, in cases of slow oozing after polypectomy, the mucosal defect can be gently and directly suctioned with the scope tip for 30-60 s. This direct pressure on small bleeding capillaries often results in effective hemostasis.

When a more brisk or persistent immediate PPB is encountered, it is essential to have an effective field of view. For this, a water jet on the colonoscope is helpful, to allow for continued lavage of the bleeding site in order to identify the precise location of the bleeding source. Identifying a bleeding source is important for the targeted deployment of endoscopic therapy. The most commonly utilized option for significant immediate PPB is the use of through-the-scope (TTS) clips. In previous studies, the rate of endoscopic success with TTS clips has been high, with cessation of bleeding achieved in the vast majority of patients. ${ }^{64,65}$ In the series by Parra-Blanco et al., ${ }^{65}$ there were no cases of recurrent bleeding.

The preferred method for deploying a clip in treating bleeding from the stalk of a pedunculated polyp is by deploying the clip perpendicular to the base of the stalk to ligate the feeder vessels. ${ }^{66}$ For PPB occurring after sessile polyp removal, the goal is to directly tamponade the underlying blood vessel by maneuvering the clip and opposing the mucosa on both sides of the defect, when possible. ${ }^{67}$ For very large endoscopic resection, the adjacent mucosal margins may not be approximated effectively at times. To ensure hemostasis, the area should be lavaged copiously while the TTS clip is closed but not deployed. If the area has no re-accumulation of red blood, then clip deployment is appropriate in that position. ${ }^{67}$

Other methods of endoscopic hemostasis include direct thermal therapy, which is performed with bipolar cautery, snare tip, or thermal probes. In addition, for refractory oozing PPB, coagulation therapy with argon plasma coagulation can be applied to the resection bed. The electrosurgical settings vary depending on the preference of the provider and the system used; however, generally, caution should be exercised when performing thermal therapy in the right colon and cecum, given the thin colonic wall in the region. ${ }^{68}$ There are no head-to-head prospective studies comparing thermal therapy to TTS clips for the management of PPB. The decision to use a certain method will depend on the clinical scenario, available equipment, and preference of the endoscopist. For

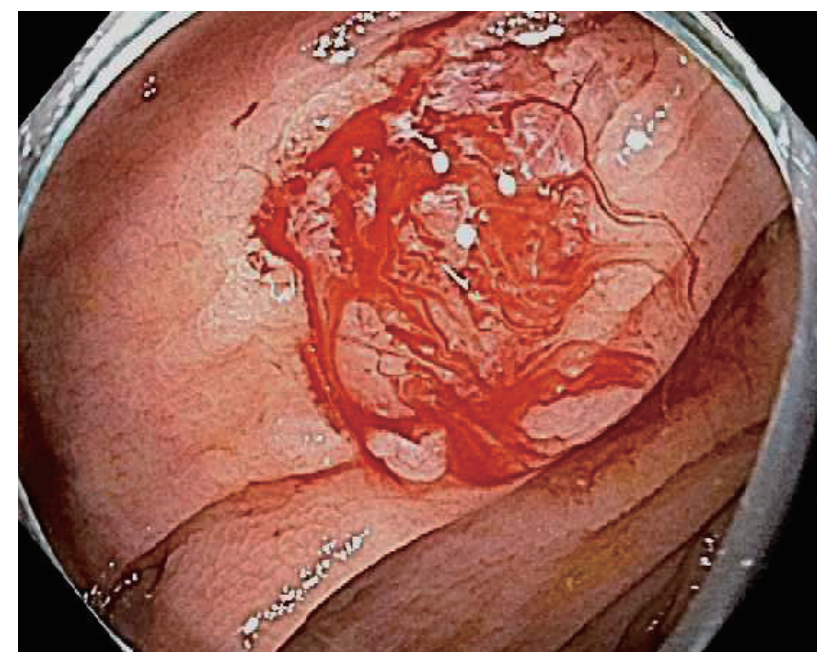

Fig. 2. Scant oozing from the mucosal resection site after cold-snare polypectomy. 
instance, intraprocedural bleeding during large-polyp EMR can be effectively treated with snare-tip soft coagulation (STSC). This avoids the placement of TTS clips and/or larger thermal defects that can, at times, impair the effective completion of a large-polyp EMR. If STSC is not adequate, then intraprocedural bleeding during a large-polyp EMR can often be achieved using coagulating forceps. These techniques have been described in detail by Klein and Bourke. ${ }^{69}$

For either immediate or delayed PPB, if standard hemostasis therapies including TTS clip application, epinephrine solution injection, thermal/coagulative therapy, and/or combinations thereof do not achieve hemostasis, there are newer hemostasis products available that can be utilized. The over-the-scope clip (OTSC; Ovesco Endoscopy, Tubingen, Germany) has been more extensively studied in the treatment of upper gastrointestinal bleeding but has also been demonstrated to be an effective salvage therapy option in patients with $\mathrm{PPB}^{70-73}$ Moreover, contact hemostasis powder spray (Hemospray; Cook Medical, Bloomington, IN, USA) has been used to successfully treat $\mathrm{PPB}^{74-77}$ Given that hemostasis powder will slough off some interval after treatment, studies ${ }^{76,77}$ have shown higher rates of re-bleeding within the first $72 \mathrm{~h}$ and that re-bleeding is more likely to occur with an actively spurting bleed and with a background of hemodynamic instability. It is, therefore, recommended to use Hemospray as a temporary bridge to a more definitive treatment and to repeat colonoscopy in 24-48 $\mathrm{h}$ after achieving initial hemostasis to perform definitive endoscopic therapy.

In cases of delayed $\mathrm{PPB}$, the site of active bleeding can be endoscopically determined by repeating a colonoscopy or nonendoscopically via angiography or red blood cell nuclear scintigraphy. ${ }^{78}$ Although most cases of delayed PPB can be effectively managed endoscopically, the decision to proceed with colonoscopy and the timing of colonoscopy should be individualized. First, the patient should be assessed for hemodynamic instability (including orthostasis) and the duration, frequency, and volume of hematochezia, in addition to laboratory evaluation with complete blood count and prothrombin time/international normalized ratio. Resuscitation of blood volume and infusion of crystalloid to achieve hemodynamic stability should be prioritized.

Sonnenberg ${ }^{79}$ conducted a decision analysis study and showed that proceeding with colonoscopy for delayed PPB was beneficial in identifying and treating a bleeding lesion in $22 \%$ of the cases, with a number needed to treat of 4.5 patients. The author concluded that it would be beneficial to attempt a repeat colonoscopy, but, at the same time, it is reasonable to manage some patients expectantly. In a study by Derbyshire et al., the requirement for blood transfusion and a drop in hemoglobin of $>2 \mathrm{~g} / \mathrm{dL}$ were predictors of the need for a therapeutic intervention. ${ }^{2} \mathrm{Ma}$ and Bourke proposed an algorithm for the management of bleeding after large-polyp EMR. ${ }^{67}$ In this algorithm, the authors recommended bowel preparation and colonoscopy for patients with ongoing bleeding, and found that the factors associated with poor outcome were American Society of Anesthesiologists grade $\geq 2$, hemodynamic instability, hourly or more frequent hematochezia, low admission hemoglobin $(<12.0 \mathrm{~g} / \mathrm{dL})$, or the requirement for blood transfusion. ${ }^{67}$ Generally, an expedited bowel preparation followed by expeditious diagnostic and therapeutic colonoscopy once a patient is stabilized is appropriate. When the culprit polypectomy site is found, we recommend clearing the area of any residual blood and blood clot in order to identify the precise source of bleeding within the polypectomy defect. The area can be subsequently treated with clips or forceps coagulation or some combination with epinephrine injection. ${ }^{67,68,80}$ In general, extensive thermal therapy is discouraged in a post-polypectomy resection site to avoid the risk of delayed perforation, as the mucosal resection site is often ulcerated. As mentioned previously, the use of OTSCs or hemostatic powder can be considered for refractory bleeding lesions. For patients that remain hemodynamically unstable despite resuscitative efforts, consultations for urgent interventional radiology evaluation and/or urgent surgical evaluation are prudent.

\section{CONCLUSIONS}

PPB is one of the most common complications of endoscopic polypectomy. There are multiple risk factors related to patient and polyp characteristics that should be considered. In most cases, immediate PPB can be effectively managed endoscopically when recognized and managed promptly. Delayed PPB can manifest in a myriad of ways. In severe delayed PPB, resuscitation for hemodynamic stabilization should be prioritized, followed by endoscopic evaluation and therapy once the patient is stabilized. CSP for sessile polyps $<20 \mathrm{~mm}$ seems to be safe and has a lower incidence of delayed PPB. Future areas of research in PPB include the risks of DOACs, risks of specific electrosurgical settings (HSP vs. CSP), and prospective comparative evaluation of newer hemostasis agents (hemostatic spray powder, OTSC, etc.).

\section{Conflicts of Interest}

The authors have no financial conflicts of interest.

Acknowledgements

We thank Antonios Wehbeh for input to an early draft of the manuscript. 


\section{REFERENCES}

1. Zauber AG, Winawer SJ, O'Brien MJ, et al. Colonoscopic polypectomy and long-term prevention of colorectal-cancer deaths. N Engl J Med 2012;366:687-696.

2. Derbyshire E, Hungin P, Nickerson C, Rutter MD. Post-polypectomy bleeding in the English National Health Service Bowel Cancer Screening Programme. Endoscopy 2017;49:899-908.

3. Hassan C, Repici A, Sharma P, et al. Efficacy and safety of endoscopic resection of large colorectal polyps: a systematic review and meta-analysis. Gut 2016;65:806-820.

4. Kim HS, Kim TI, Kim WH, et al. Risk factors for immediate postpolypectomy bleeding of the colon: a multicenter study. Am J Gastroenterol 2006;101:1333-1341.

5. Zhang Q, An S, Chen Z, et al. Assessment of risk factors for delayed colonic post-polypectomy hemorrhage: a study of 15553 polypectomies from 2005 to 2013. PLoS One 2014;9:e108290.

6. Buddingh KT, Herngreen T, Haringsma J, et al. Location in the right hemi-colon is an independent risk factor for delayed post-polypectomy hemorrhage: a multi-center case-control study. Am J Gastroenterol 2011;106:1119-1124.

7. Rutter MD, Nickerson C, Rees CJ, Patnick J, Blanks RG. Risk factors for adverse events related to polypectomy in the English Bowel Cancer Screening Programme. Endoscopy 2014;46:90-97.

8. Pigò F, Bertani H, Grande G, Abate F, Vavassori S, Conigliaro RL. Post-polypectomy bleeding after colonoscopy on uninterrupted aspirin/ non steroideal antiflammatory drugs: systematic review and meta-analysis. Dig Liver Dis 2018;50:20-26.

9. Shalman D, Gerson LB. Systematic review with meta-analysis: the risk of gastrointestinal haemorrhage post-polypectomy in patients receiving anti-platelet, anti-coagulant and/or thienopyridine medications. Aliment Pharmacol Ther 2015;42:949-956.

10. Gandhi S, Narula N, Mosleh W, Marshall JK, Farkouh M. Meta-analysis: colonoscopic post-polypectomy bleeding in patients on continued clopidogrel therapy. Aliment Pharmacol Ther 2013;37:947-952.

11. Ishigami $\mathrm{H}$, Arai $\mathrm{M}$, Matsumura $\mathrm{T}$, et al. Heparin-bridging therapy is associated with a high risk of post-polypectomy bleeding regardless of polyp size. Dig Endosc 2017;29:65-72.

12. Shibuya T, Nomura O, Kodani T, et al. Continuation of antithrombotic therapy may be associated with a high incidence of colonic post-polypectomy bleeding. Dig Endosc 2017;29:314-321.

13. Sakai T, Nagami Y, Shiba M, et al. Heparin-bridging therapy is associated with post-colorectal polypectomy bleeding in patients whose oral anticoagulation therapy is interrupted. Scand J Gastroenterol 2018;53:13041310.

14. Yoshimura D, Ochiai T, Fukuda S-I, et al. Perioperative heparin bridging for colorectal EMR or ESD for patients receiving anticoagulation resulted in a very high incidence of bleeding complication. Gastrointest Endosc 2018;87(6 Suppl):AB508.

15. Hui AJ, Wong RM, Ching JY, Hung LC, Chung SC, Sung JJ. Risk of colonoscopic polypectomy bleeding with anticoagulants and antiplatelet agents: analysis of 1657 cases. Gastrointest Endosc 2004;59:44-48.

16. Lin D, Soetikno RM, McQuaid K, et al. Risk factors for postpolypectomy bleeding in patients receiving anticoagulation or antiplatelet medications. Gastrointest Endosc 2018;87:1106-1113.

17. Park SK, Seo JY, Lee MG, et al. Prospective analysis of delayed colorectal post-polypectomy bleeding. Surg Endosc 2018;32:3282-3289.

18. Beppu K, Yokoi K, Yamagata H, Suzuki S, Ogihara T. What kind of direct oral anticoagulant presents the lowest bleeding risk after endoscopic resection of colorectal polyps? Gastrointest Endosc 2019;89(6 Suppl):AB87.

19. Yanagisawa N, Nagata N, Watanabe K, et al. Post-polypectomy bleeding and thromboembolism risks associated with warfarin vs direct oral anticoagulants. World J Gastroenterol 2018;24:1540-1549.

20. Fukunaga S, Nagami Y, Ohira M, et al. Orbit score predicts major bleed- ing after colorectal polypectomy in patients receiving oral anticoagulation therapy. Gastrointest Endosc 2019;89(6 Suppl):AB381.

21. Lei T, Lu Q, Ma H, Yang J. The establishment of risk-scoring model for colorectal post-polypectomy bleeding in ambulatory surgery unit. Gastrointest Endosc 2019;89(6 Suppl):AB444.

22. Baron TH, Kamath PS, McBane RD. Management of antithrombotic therapy in patients undergoing invasive procedures. N Engl J Med 2013;368:2113-2124.

23. ASGE Standards of Practice Committee, Acosta RD, Abraham NS, et al. The management of antithrombotic agents for patients undergoing GI endoscopy. Gastrointest Endosc 2016;83:3-16.

24. Veitch AM, Vanbiervliet G, Gershlick AH, et al. Endoscopy in patients on antiplatelet or anticoagulant therapy, including direct oral anticoagulants: British Society of Gastroenterology (BSG) and European Society of Gastrointestinal Endoscopy (ESGE) guidelines. Endoscopy 2016;48:c1.

25. Fujimoto K, Fujishiro M, Kato M, et al. Guidelines for gastroenterological endoscopy in patients undergoing antithrombotic treatment. Dig Endosc 2014;26:1-14.

26. Kato M, Uedo N, Hokimoto S, et al. Guidelines for gastroenterological endoscopy in patients undergoing antithrombotic treatment: 2017 appendix on anticoagulants including direct oral anticoagulants. Dig Endosc 2018;30:433-440.

27. Chan FKL, Goh KL, Reddy N, et al. Management of patients on antithrombotic agents undergoing emergency and elective endoscopy: joint Asian Pacific Association of Gastroenterology (APAGE) and Asian Pacific Society for Digestive Endoscopy (APSDE) practice guidelines. Gut 2018;67:405-417.

28. Yamashina T, Fukuhara M, Maruo T, et al. Cold snare polypectomy reduced delayed postpolypectomy bleeding compared with conventional hot polypectomy: a propensity score-matching analysis. Endosc Int Open 2017;5:E587-E594.

29. Repici A, Hassan C, Vitetta E, et al. Safety of cold polypectomy for $<10 \mathrm{~mm}$ polyps at colonoscopy: a prospective multicenter study. Endoscopy 2012;44:27-31.

30. Shinozaki S, Kobayashi Y, Hayashi Y, Sakamoto H, Lefor AK, Yamamoto $\mathrm{H}$. Efficacy and safety of cold versus hot snare polypectomy for resecting small colorectal polyps: systematic review and meta-analysis. Dig Endosc 2018;30:592-599.

31. Suzuki S, Gotoda T, Kusano C, et al. Width and depth of resection for small colorectal polyps: hot versus cold snare polypectomy. Gastrointest Endosc 2018;87:1095-1103.

32. Ferlitsch M, Moss A, Hassan C, et al. Colorectal polypectomy and endoscopic mucosal resection (EMR): European Society of Gastrointestinal Endoscopy (ESGE) clinical guideline. Endoscopy 2017;49:270-297.

33. Qu J, Jian $\mathrm{H}$, Li L, et al. Effectiveness and safety of cold versus hot snare polypectomy: a meta-analysis. J Gastroenterol Hepatol 2019;34:49-58.

34. Kawamura T, Takeuchi Y, Asai S, et al. A comparison of the resection rate for cold and hot snare polypectomy for 4-9 $\mathrm{mm}$ colorectal polyps: a multicentre randomised controlled trial (CRESCENT study). Gut 2018;67:1950-1957.

35. Jegadeesan R, Aziz M, Desai M, et al. Hot snare vs. cold snare polypectomy for endoscopic removal of 4 - $10 \mathrm{~mm}$ colorectal polyps during colonoscopy: a systematic review and meta-analysis of randomized controlled studies. Endosc Int Open 2019;7:E708-E716.

36. Thoguluva Chandrasekar V, Spadaccini M, Aziz M, et al. Cold snare endoscopic resection of nonpedunculated colorectal polyps larger than $10 \mathrm{~mm}$ : a systematic review and pooled-analysis. Gastrointest Endosc 2019;89:929-936.e3.

37. Spadaccini M, Chandrasekar VT, Aziz M, et al. Endoscopic removal of colorectal polyps $\geq 10 \mathrm{~mm}$ using cold-snare resection techniques: a systematic review and pooled-analysis of the published literature. Gastrointest Endosc 2019;89(6 Suppl):AB401.

38. Kaltenbach TR, Keswani RN, Nguyen-Vu T, et al. Cold snare polypectomy appears safe for the resection of small pedunculated polyps. Gastro- 
intest Endosc 2019;89(6 Suppl):AB382-AB383.

39. Aizawa M, Utano K, Nemoto D, et al. Delayed hemorrhage after cold snare polypectomy in patients receiving antithrombotic therapy: an observational study of 2152 patients. Gastrointest Endosc 2019;89(6 Suppl):AB87.

40. Higurashi T, Ashikari K, Arimoto J, Ohkubo H, Nakajima A. Cold snare polypectomy is safety procedutr with not only warfarin but also DOAC continuation. Gastrointest Endosc 2019;89(6 Suppl):AB412.

41. Matsumoto M, Yoshii S, Shigesawa T, et al. Safety of cold polypectomy for colorectal polyps in patients on antithrombotic medication. Digestion 2018;97:76-81.

42. Shimodate Y, Takeuchi Y, Mabe K, et al. A multicecter, randomized open-label trial comparing heparin bridging with hot snare polypectomy and continuous oral administration of anticoagulants with cold snare polypectomy for patients with colorectal polyps smaller than 10mm. (C-PAC trial). Gastrointest Endosc 2019;89(6 Suppl):AB86.

43. Horiuchi A, Nakayama Y, Kajiyama M, Tanaka N, Sano K, Graham DY. Removal of small colorectal polyps in anticoagulated patients: a prospective randomized comparison of cold snare and conventional polypectomy. Gastrointest Endosc 2014;79:417-423.

44. Arimoto J, Chiba H, Ashikari K, et al. Safety of cold snare polypectomy in patients receiving treatment with antithrombotic agents. Dig Dis Sci 2019 Jan 25 [Epub]. https://doi.org/10.1007/s10620-019-5469-1.

45. Liaquat H, Rohn E, Rex DK. Prophylactic clip closure reduced the risk of delayed postpolypectomy hemorrhage: experience in 277 clipped large sessile or flat colorectal lesions and 247 control lesions. Gastrointest Endosc 2013;77:401-407.

46. Matsumoto M, Kato M, Oba K, et al. Multicenter randomized controlled study to assess the effect of prophylactic clipping on post-polypectomy delayed bleeding. Dig Endosc 2016;28:570-576.

47. Akhter A, Benson M, Gopal DV, Soni A, Weiss J, Pfau P. Prospective study of variation in endoscopic clip use post-polypectomy and impact on gastrointestinal bleeding. Gastrointest Endosc 2019;89(6 Sup$\mathrm{pl}): \mathrm{AB} 404$

48. Forbes N, Hilsden R, Maxwell C, et al. Prophylactic endoscopic clipping is ineffective in the prevention of delayed post-polypectomy bleeding in routine clinical practice. Gastrointest Endosc 2019;89(6 Suppl):AB120.

49. Pohl H, Grimm IS, Moyer MT, et al. Clip closure prevents bleeding after endoscopic resection of large colon polyps in a randomized trial. Gastroenterology 2019 Mar 15 [Epub]. https://doi.org/10.1053/j.gastro.2019.03.019.

50. Feagins LA, Smith AD, Kim D, et al. A prospective, randomized trial of prophylactic hemoclipping for preventing delayed post-polypectomy bleeding in patients with large colonic polyps. Gastrointest Endosc 2019;89(6 Suppl):AB119.

51. Bhurwal A, Gaidhane M, Tawadros A, et al. To clip or not clip: a meta analysis of RCTs to evalute the impact of prophylactic clipping for delayed post polypectomy bleeding. Gastrointest Endosc 2019;89(6 Suppl):AB373-AB374.

52. Mangira D, Ket SN, Majeed A, Gibson PR, Brown G. Postpolypectomy prophylactic clip closure for the prevention of delayed postpolypectomy bleeding: a systematic review. JGH Open 2018;2:105-110.

53. Boumitri C, Mir FA, Ashraf I, et al. Prophylactic clipping and post-polypectomy bleeding: a meta-analysis and systematic review. Ann Gastroenterol 2016;29:502-508.

54. Nishizawa T, Suzuki H, Goto O, Ogata H, Kanai T, Yahagi N. Effect of prophylactic clipping in colorectal endoscopic resection: a meta-analysis of randomized controlled studies. United European Gastroenterol J 2017;5:859-867.

55. Ayoub F, Westerveld DR, Forde JJ, Forsmark CE, Draganov PV, Yang D. Effect of prophylactic clip placement following endoscopic mucosal resection of large colorectal lesions on delayed polypectomy bleeding: a meta-analysis. World J Gastroenterol 2019;25:2251-2263.

56. Forbes N, Frehlich L, James MT, et al. Routine prophylactic endoscopic clipping is not efficacious in the prevention of delayed post-polypec- tomy bleeding: a systematic review and meta-analysis of randomized controlled trials. J Can Assoc Gastroenterol 2019;2:105-117.

57. Jensen DM, Jutabha R, Sul J, Kim S, Marya NB. A targetted approach to risk stratification and prevention of delayed post-polypectomy hemorrhage in high risk patients after removal of benign colon polyps. Gastrointestinal Endoscopy 2019;89(6 Suppl):AB121.

58. Pohl H, Grimm IS, Moyer MT, et al. Electrocautery setting does not affect efficacy and safety of endoscopic resection of large colorectal polyps. Endoscopy 2019;51:S32-S33.

59. Dobrowolski S, Dobosz M, Babicki A, Dymecki D, Hać S. Prophylactic submucosal saline-adrenaline injection in colonoscopic polypectomy: prospective randomized study. Surg Endosc 2004;18:990-993.

60. Hsieh YH, Lin HJ, Tseng GY, et al. Is submucosal epinephrine injection necessary before polypectomy? A prospective, comparative study. Hepatogastroenterology 2001;48:1379-1382.

61. Lee SH, Chung IK, Kim SJ, et al. Comparison of postpolypectomy bleeding between epinephrine and saline submucosal injection for large colon polyps by conventional polypectomy: a prospective randomized, multicenter study. World J Gastroenterol 2007;13:2973-2977.

62. Paspatis GA, Paraskeva K, Theodoropoulou A, et al. A prospective, randomized comparison of adrenaline injection in combination with detachable snare versus adrenaline injection alone in the prevention of postpolypectomy bleeding in large colonic polyps. Am J Gastroenterol 2006;101:2805; quiz 2913.

63. Park CH, Jung YS, Nam E, Eun CS, Park DI, Han DS. Comparison of efficacy of prophylactic endoscopic therapies for postpolypectomy bleeding in the colorectum: a systematic review and network meta-analysis. Am J Gastroenterol 2016;111:1230-1243.

64. Binmoeller KF, Thonke F, Soehendra N. Endoscopic hemoclip treatment for gastrointestinal bleeding. Endoscopy 1993;25:167-170.

65. Parra-Blanco A, Kaminaga N, Kojima T, et al. Hemoclipping for postpolypectomy and postbiopsy colonic bleeding. Gastrointest Endosc 2000;51:37-41.

66. Hokama A, Kishimoto K, Kinjo F, Fujita J. Endoscopic clipping in the lower gastrointestinal tract. World J Gastrointest Endosc 2009;1:7-11.

67. Ma MX, Bourke MJ. Complications of endoscopic polypectomy, endoscopic mucosal resection and endoscopic submucosal dissection in the colon. Best Pract Res Clin Gastroenterol 2016;30:749-767.

68. Hong SP. How do I manage post-polypectomy bleeding? Clin Endosc 2012;45:282-284.

69. Klein A, Bourke MJ. Advanced polypectomy and resection techniques. Gastrointest Endosc Clin N Am 2015;25:303-333.

70. Jayaraman V, Hammerle C, Lo SK, Jamil L, Gupta K. Clinical application and outcomes of over the scope clip device: initial US experience in humans. Diagn Ther Endosc 2013;2013:381873.

71. Alcaide N, Peñas-Herrero I, Sancho-del-Val L, Ruiz-Zorrilla R, Barrio J, Pérez-Miranda M. Ovesco system for treatment of postpolypectomy bleeding after failure of conventional treatment. Rev Esp Enferm Dig 2014;106:55-58.

72. Brandler J, Baruah A, Zeb M, et al. Efficacy of over-the-scope clips in management of high-risk gastrointestinal bleeding. Clin Gastroenterol Hepatol 2018;16:690-696.el.

73. Lamberts R, Koch A, Binner C, et al. Use of over-the-scope clips (OTSC) for hemostasis in gastrointestinal bleeding in patients under antithrombotic therapy. Endosc Int Open 2017;5:E324-E330.

74. Hookey L, Barkun A, Sultanian R, Bailey R. Successful hemostasis of active lower GI bleeding using a hemostatic powder as monotherapy, combination therapy, or rescue therapy. Gastrointest Endosc 2019;89:865-871.

75. Ivekovic H, Bilic B, Markos P, Rustemovic N, Ostojic R, Mönkemüller K. Successful use of Hemospray to control refractory post-polypectomy bleeding. Endoscopy 2015;47 Suppl 1 UCTN:E466-E467.

76. Chahal D, Ali-Mohamad N, Donnellan F. Clinical outcomes of hemospray use in upper \& lower gastrointestinal bleeding. Gastrointest Endosc 2019;89(6 Suppl):AB568. 


\section{Ce cumcen Enooscopy}

77. Rodríguez de Santiago E, Burgos-Santamaria D, Pérez-Carazo L, et al. Hemostatic spray powder TC-325 for GI bleeding in a nationwide study: survival and predictors of failure via competing risks analysis. Gastrointest Endosc 2019 Jun 17 [Epub]. https://doi.org/10.1016/ j.gie.2019.06.008

78. ASGE Standards of Practice Committee, Fisher DA, Maple JT, et al
Complications of colonoscopy. Gastrointest Endosc 2011;74:745-752.

79. Sonnenberg A. Management of delayed postpolypectomy bleeding: a decision analysis. Am J Gastroenterol 2012;107:339-342.

80. Strate LL, Gralnek IM. ACG clinical guideline: management of patients with acute lower gastrointestinal bleeding. Am J Gastroenterol 2016;111:755. 